Argumentation Argumentation et Analyse du Discours

\title{
serça, Isabelle. 2012. Esthétique de la ponctuation (Paris : Gallimard, coll. Blanche)
}

\section{Gilles Philippe}

\section{(2) OpenEdition}

Journals

Édition électronique

URL : http://journals.openedition.org/aad/1434

DOI $\cdot 10.4000 /$ aad 1434

ISSN : 1565-8961

\section{Éditeur}

Université de Tel-Aviv

\section{Référence électronique}

Gilles Philippe, «serça, Isabelle. 2012. Esthétique de la ponctuation (Paris : Gallimard, coll. Blanche)», Argumentation et Analyse du Discours [En ligne], 10 | 2013, mis en ligne le 10 avril 2013, consulté le 22 septembre 2020. URL : http://journals.openedition.org/aad/1434; DOI : https://doi.org/10.4000/aad 1434

Ce document a été généré automatiquement le 22 septembre 2020.

\section{cc) $(1) \odot$}

Argumentation \& analyse du discours est mis à disposition selon les termes de la licence Creative

Commons Attribution - Pas d'Utilisation Commerciale - Pas de Modification 4.0 International. 


\title{
serça, Isabelle. 2012. Esthétique de la ponctuation (Paris : Gallimard, coll. Blanche)
}

\author{
Gilles Philippe
}

\section{RÉFÉRENCE}

serça, Isabelle. 2012. Esthétique de la ponctuation (Paris : Gallimard, coll. Blanche), 308 pages, ISBN : 9782070137640

1 On s'étonne d'abord de trouver un essai savant voire pointu sous cette couverture «blanche » de la NRF qui protège habituellement des romans ou des proses d'allures moins austères. Puis, rapidement, le charme opère. De fait, on pourrait d'abord définir le livre d'Isabelle Serça par ce qu'il n'est pas : un traité de ponctuation, une histoire des usages typographiques, une synthèse des pratiques stylistiques. De tels ouvrages existent déjà ; celui-ci en est nourri, mais il en diffère. Le premier mot du titre n'est pourtant pas une simple esquive, qui diluerait dans une problématique large des considérations impressionnistes. Tout au contraire, il indique que le propos n'oublie jamais que la catégorie de ponctuation n'appartient pas prioritairement aux genres verbaux, mais qu'elle est convoquée avec la même pertinence pour décrire des productions musicales, architecturales ou plastiques.

2 On se contentera cependant ici de n'envisager que les pages, de fait les plus nombreuses, que l'ouvrage consacre à la ponctuation de la prose littéraire, et même tout particulièrement à la ponctuation des textes romanesques au $20^{\mathrm{e}}$ siècle. Bien sûr, Isabelle Serça n'en vient pas de façon immédiate ou abrupte aux trois corpus qui sont au cœur de son analyse : les fictions de Marcel Proust, de Claude Simon et de Julien Gracq. Elle rappelle d'abord avec une grande finesse la manière dont le ponctuant a été et reste chargé d'inscrire le temps dans l'espace (« la ponctuation réfère ainsi à l'espace et au temps, qu'elle distribue selon des rapports singuliers", p.33), mais aussi 
d'inscrire dans la chaîne écrite la prosodie de la parole vive (« La définition du champ que recouvre la ponctuation dépend en fait du rapport à l'oral que pose la théorie ", p. 66).

3 On peut certes résister à certaines considérations liminaires qui vont engager, dans un deuxième temps, une réelle stylistique de la ponctuation : «Les écrivains créent leur propre ponctuation, partie prenante de leur style, en transgressant les règles du code » (p. 71). Est-ce toujours vrai ? N'est-ce pas lire les textes avec le monocle moderniste qui a fait du singulier et de l'originalité les deux seules catégories pertinentes pour appréhender le style? Concédons, en tout cas, qu'une telle entrée sert parfaitement les analyses des corpus retenus, qu'éclairent aussi de remarquables aperçus historiques sur la façon dont le $19^{\mathrm{e}}$ siècle a vu l'émergence d'une ponctuation proprement littéraire. Cette histoire se confond pour partie avec celle de l'imaginaire de la "voix ", et pour partie avec celle des genres, car si la poésie a radicalisé l'expérimentation sur la ponctuation, celle-ci est plus importante encore dans le travail de la prose, parce qu'elle introduit de la discontinuité dans du continu.

4 Malgré son ambition et son ampleur de vue, l'essai d'Isabelle Serça ne prétend en aucun cas épuiser une matière inépuisable. Ses entrées sont nettes. Ce qui l'intéresse, c'est la phrase longue, formée aux bouches des titans, non l'émiettement au souffle court du style coupé. Elle ne s'arrête d'ailleurs guère sur l'entre-deux du point-virgule. Mieux encore, plus que la virgule ou le point, c'est la parenthèse qui la retient, et - quand elle étudie les manuscrits -, c'est l'ajout et non le déplacement des groupes qui l'arrête. Apparaît alors que tout déploiement d'un propos en phrase engage nécessairement l'imaginaire, singulier ou collectif, d'un rapport spatialisé au temps.

Un livre d'une grande érudition, proposant un dialogue serré avec l'analyse stylistique la plus récente, mais rédigé d'une plume alerte, d'une technicité tempérée et illustrée d'exemples admirablement choisis. Une vraie réussite.

\section{AUTEURS}

\section{GILLES PHILIPPE}

Université de Lausanne 